\title{
Knowledge Sharing, Organizational Learning and Service Innovation in Tourism
}

\author{
Yong Rao, Manni Yang, Yuexuan Yang \\ School of Tourism Management, Sun Yat-sen University, Guangzhou, China \\ Email: raoyong@vip.163.com
}

How to cite this paper: Rao, Y., Yang, M.N. and Yang, Y.X. (2018) Knowledge Sharing, Organizational Learning and Service Innovation in Tourism. Journal of Service Science and Management, 11, 510-526. https://doi.org/10.4236/jssm.2018.115035

Received: September 3, 2018

Accepted: October 15, 2018

Published: October 18, 2018

Copyright $\odot 2018$ by authors and Scientific Research Publishing Inc. This work is licensed under the Creative Commons Attribution International License (CC BY 4.0).

http://creativecommons.org/licenses/by/4.0/

(c) (i) Open Access

\begin{abstract}
Knowledge sharing is a key factor that influences the organizational learning, service innovation and competitive advantage of tourism enterprises. Despite the fruitful research achievements in knowledge sharing since the 1990s, there is no appropriate framework to effectively summarize existing research literature due to the complexity of the tourism knowledge system. This article, based on the research path of knowledge sharing, summarizes the knowledge sharing research literature in tourism industry according to the framework of "organizational learning - service innovation - competitive advantage", and analyzes the research results of the relationship between knowledge sharing and organizational learning, knowledge sharing and service innovation as well as knowledge sharing and competitive advantage. On this basis, this article further analyzes the role and function of knowledge sharing in the closed loop of "organizational learning - service innovation - competitive advantage", with the aim of providing reference for knowledge sharing research in tourism.
\end{abstract}

\section{Keywords}

Tourism Industry, Knowledge Sharing, Organizational Learning, Service Innovation

\section{Introduction}

This paper reviews the studies of knowledge sharing in tourism. As an essential part of knowledge management research, knowledge sharing has definitely received much attention in both academia and industry, especially for Knowledge Intensive Business Services (KIBS) industry which is heavily reliant on professional knowledge and concerned with providing knowledge-intensive support. Although tourism does not belong to traditional KIBS, there exists a great deal of 
knowledge creation in the industry. Knowledge sharing has gradually been regarded as an important factor that stimulates the innovation and development of tourism industry as well as promotes the service level of hospitality [1] [2]. In addition, as tourism belongs to labor-intensive industry, the industrial activities mainly rely on interpersonal communication and interaction. Therefore, the majority of the knowledge created in tourism is tacit knowledge as with the theoretical understanding of a subject that is difficult to transfer to another person by means of writing it down or verbalizing it. Since tacit knowledge itself is usually complicated, the formalized mechanism of externalization and storage of tacit knowledge is still lacking [3]. Furthermore, the knowledge creation within tourism industry heavily relies on personal tacit knowledge. If there is no enough stimulation and motivation, the efficiency of personal knowledge sharing would be greatly reduced, which may even result to the invalid knowledge creation. Therefore, it is necessary for tourism enterprises to involve as the third party so as to moderate the knowledge sharing process, which may further perplex the research problem.

Above all, considering the complexity of knowledge sharing mechanism as well as the lack of suitable research framework to integrate the present studies in tourism industry, it is imperative to do a further and synthesized study in order to better solve the actual problem during the practice. This paper will have a thorough review of relevant literature and hope to clarify the constructive role that the knowledge sharing plays in tourism enterprises.

\section{Conceptual Framework}

For the sake of the quality of our reviewed literature, this paper used the core database in Web of Science as the main source of literature, with the keywords of "knowledge sharing" and "tourism" or "hospitality". In order to conduct a comprehensive and systematic review of the existing researches, we also picked out some highly-cited articles from the references to enrich our retrieval results. After the outputs of conferences, forums and books were deleted, 57 articles were finally obtained. Furthermore, through a sketchy glance over all the papers, some tangential articles that are irrelevant with the subject were deleted, leaving 40 articles as the research object of this paper.

Olsen and Connolly [4] studied the relationship between technology innovation and the capacity of developing employees' tacit knowledge within tourist enterprises, which opened up the research about knowledge sharing in tourism. Afterwards, studies increased rapidly and there came out many classical literature within the next three years, of which the research content included knowledge sharing and touristic destination, knowledge sharing and enterprises innovation, knowledge sharing and employee innovation, knowledge sharing and hotel customer relationship management and so force [5] [6] [7] [8]. On this basis, an increasing number of scholars began to study the function and acting path of knowledge sharing in tourism [9] [10] [11] [12] [13]. As the research 
moved along, some scholars gradually focused on the whole industry to learn the new trends of knowledge sharing [14] [15] [16]. Obviously, from the perspective of tourism industry, knowledge sharing is crucial in promoting industrial information communication and cost controlling. However, as tourism industry is made up of touristic enterprises, it is extremely essential to do knowledge sharing researches based on the context of enterprises. Thereafter, many scholars turned to focus on touristic companies in order to explore the function of knowledge sharing in the dimension of organizational learning and service innovation as well as to see how knowledge sharing could be transformed into corporate competitive advantage. To sum up, existing studies on tourism knowledge sharing were developed along two routes. The first route was to discuss the relationship between knowledge sharing activities and organizational learning in touristic enterprises. The result shows that knowledge sharing could increase the breadth and depth of organizational learning and create a constructive learning atmosphere among employees [17] [18]. The other route was to explore how knowledge sharing behavior could influence service innovation in touristic enterprises. It is believed that internal knowledge sharing could accelerate knowledge interaction and application, which expands employees' knowledge network and stimulate their innovative behavior. In other words, innovation relies on the creation of new knowledge and knowledge sharing could bring out knowledge innovation, which exactly meets the prerequisite of service innovation [19].

As we can see from the aforementioned research transition, knowledge sharing has come to an essential factor influencing organizational learning and service innovation, which further produces a competitive edge for touristic enterprise. Therefore, a summarized framework that contains these three core elements, organizational learning, service innovation and competitive advantage, should be established so that we could effectively tease out and conclude the academic outputs of tourism knowledge sharing. Given the above, the review of knowledge sharing studies in tourism will be organized under the framework of three main parts which includes knowledge sharing and organizational learning, knowledge sharing and service innovation as well as knowledge sharing and competitive advantage. First of all, the paper will begin with an overview of the mechanism of knowledge sharing in tourism activities.

\section{Mechanism of Knowledge Sharing in Tourism}

The two patterns of knowledge sharing mechanism are peer sharing and master-prentice succession (Figure 1). Knowledge sharing is the process that experience, information, skills and expertise are exchanged, shared and transferred among organization members [20]. On the one hand, information and skills are transmitted transversely among coequals during the daily communication of employees [21]. On the other hand, expertise can be shared and inherited lengthways from master to apprentice. Throughout the process, certain factors like 


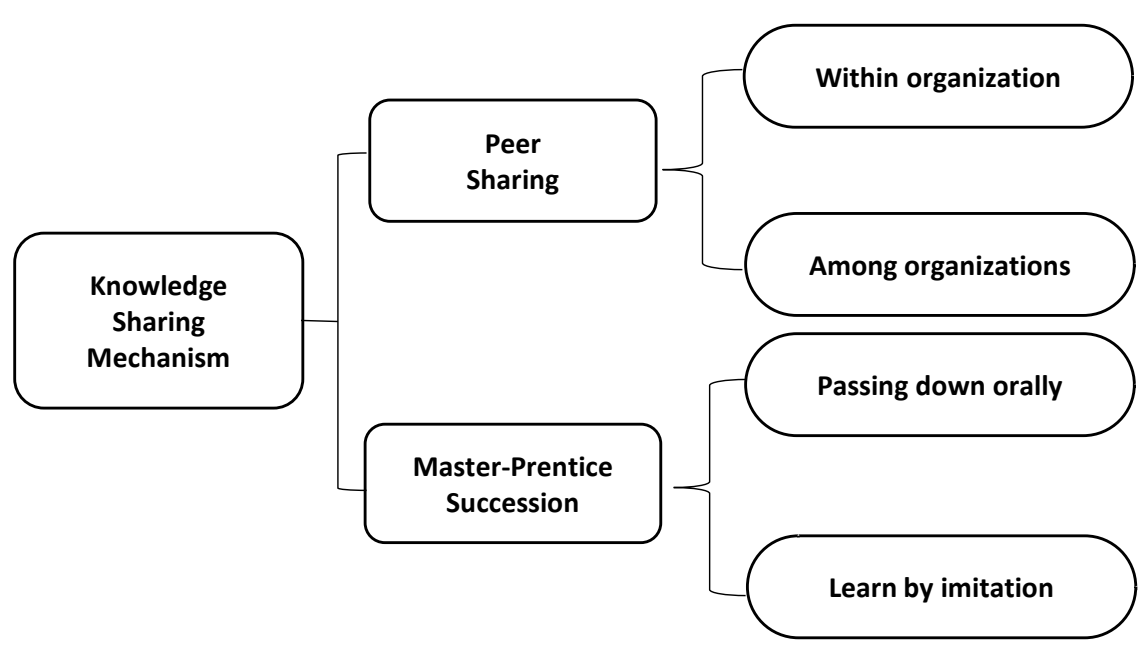

Figure 1. Two patterns of knowledge sharing mechanism in tourism.

cultural atmosphere, interpersonal relationship, social network and social trust, could support and motivate knowledge sharing.

The peer sharing of knowledge firstly occurs inside the organization. Within the hotels or travel companies, knowledge sharing happens in a formal or informal way of employees' shared behavior. The formal knowledge sharing is led by management in most cases, which includes organized experience sharing sessions or seminars among internal organization members. While the informal one is much more flexible and diverse that knowledge sharing could exist in regular gatherings or office chats and the roles of knowledge provider and recipient can be exchanged freely without any definite boundaries. Both the two ways make up the process of knowledge sharing in tourism enterprises. What's more, peering sharing can happen among organizations as well. From the horizontal perspective, in the way of industry alliance, tourism enterprises share customer information and market trends with each other in order to build up an efficient customer relationship management system and fend off the underlying threatens during operation. From the vertical perspective, by sharing knowledge with upstream and downstream partners, touristic enterprises can strengthen their industrial competitiveness. Taking travel agency as an example, the knowledge sharing with airline companies can improve the alliance and also the market competitiveness among travel agency groups [14]. On the whole, horizontal and vertical knowledge sharing behavior constitutes the process of organizational knowledge sharing in touristic enterprises.

Except for peer sharing, master-prentice succession also comes to our attention as a pattern of knowledge sharing. The apprenticeship is a common relationship that exists in the interpersonal network of touristic staffs. Since tourism belongs to labor-intensive industry and the majority of the new knowledge created during industrial activities is tacit knowledge which is not very clear and distinct, it is the most effective and common method to share the knowledge by passing down orally or learn the skills and expertise by imitation. As we can see 
from the training system in hotels nowadays, the succession from master to apprentice is a common practice in hospitality industry. As a rule, there are two training sessions which hotel newcomers should go through, that are corporate-culture training and departmental training. For the latter, it is exactly that veteran staff share and transfer their experience to new staffs by hands-on operation and explanation, which is of great significance for newcomers to learn a new skill. Nevertheless, considering the effect of knowledge sharing, it is believed that master-prentice succession is still a lower-tier method to share knowledge. The reason is that the tacit knowledge would be ingrained into the inheritance system in the long run and hard to be made explicit, which could cause the low sharing efficiency and unsustainable knowledge creation. Consequently, in order to achieve highly effective knowledge sharing in tourism, the enterprise, as a third party with distinctive characteristics, is badly needed to get involved to promote and facilitate the process of knowledge sharing by controlling its organizational factors such as cultural atmosphere, social network and social trust.

\section{Knowledge Sharing and Organizational Learning}

Organizational learning is the process of creating, retaining, and transferring knowledge within an organization. The degree of knowledge sharing is critically important for organizational learning. Employees can adjust their work attitudes by knowledge sharing, thereafter which will influence their work behavior and motivate personal innovation. In addition, knowledge sharing can deliver information within organization, which will deepen and broaden the internal learning of enterprises and form a good learning atmosphere for organizational members. Based on these findings, more and more scholars began to bring the research perspective of knowledge into management and set out to study the knowledge sharing mechanism during organizational learning.

\subsection{Knowledge Sharing and Individual Traits}

The influence process of knowledge sharing on organizational learning goes through two phases, knowledge sharing period and organizational learning period. In the stage of knowledge sharing, employees' sharing intentions are often related to their individual traits [22]. For instance, education background [23], working experience, working friendship and personal income can all significantly influence personal knowledge sharing willingness and motivations. In the aspect of sharing intention, Liu [24] selected typical international hotels in Taichung city of Taiwan as research object and found that those workers who have less working experience mostly have higher sharing intention. The results showed that the new staff tends to build the relation with other coworkers and thereby establish the tunnel of knowledge sharing. In this way, newcomers can acquire the working techniques and capability of solving problems that they prefer to learn at their earlier working stage. In the aspect of knowledge sharing motivation, studies found that "a higher vocational level" is the main sharing 
motivation for those who earn a larger income, whereas the non-management groups are more motivated to share because of "the colleagues friendship". Moreover, trust is another important factor that influences personal knowledge sharing. By testing travel-related online social network users, Bilgihan A. et al. [25] pointed out that personal trust in the quality of integrity has positive influence in knowledge sharing behavior.

\subsection{Knowledge Sharing and Management Intervention}

In the stage of organizational learning, it is difficult to realize the effective knowledge sharing spontaneously, thus enterprises need to get involved to drive the sharing process. Hence, J.T. Yang [17] suggested that managers in tourism enterprises need to establish a system that leads to a higher level of knowledge sharing among employees and subsequently facilitate the personal and organizational learning behavior. The research of Kalotina Chalkiti and Marianna Sigala are also in concert with this viewpoint. By analyzing the knowledge sharing process of online travel forums, they concluded that the leading and bridging function during knowledge sharing should be realized by managers. Furthermore, it relies on an open and diversified learning culture to make knowledge shared during the organizational learning, therefore the organization is supposed to construct an environment that makes knowledge easy to penetrate into daily jobs. It is interesting to note that the research of J.T. Yang [26] and C.S. Wan [27] supplement this opinion. They found that corporate managers are as supportive as front-line workers to create a learning culture that can provide more opportunities for employees to gain, share and store knowledge. Besides, it is obvious to see the impact of a learning culture on knowledge sharing behavior from the perspective of management. Similarly, Taegoo Terry Kim and Gyehee Lee et al. [28] believed that a hotel that adopts learning goal orientation rather than performance goal orientation managerial measures will accelerate knowledge collection and transmission and thereby contribute to employee service innovation. And they also confirmed the two most important enablers of employees' innovation behavior, which are anticipated usefulness and reciprocal relationships. From the opposite side of knowledge hiding, Zhao, Xia and He etc. [29] also supported the viewpoint. They pointed out that organizations with some high negative reciprocity beliefs or moral disengagement would make work ostracism positively related to evasive hiding and playing dumb.

In the stage of organizational learning, the third party need to be involved in encouraging personal learning that is caused by knowledge sharing and then helping to upgrade to organizational learning. Concerning this issue, Taiwanese scholar J.T. Yang adopted the method of semi-structural interview to do research at two hotels in Taiwan. To different degrees, there existed the phenomena of personal knowledge acquisition and organizational learning both in the two hotels. However, the results showed that, comparatively speaking, case A hotel had a higher organizational learning intention. After encountering the 
knowledge that relates to their work, employees in case A hotel would activate "thinking-feedback" mechanism and tried to change the situation when conditions allow so that they could deal with the contingent problems in facing different circumstances. Whereas employees in case B hotel were relatively negative and lacked the spirit of self-exploration that they chose to wait for others' explanation and assistance when acquiring and learning the new things. To conclude, knowledge sharing cannot directly trigger the organizational learning behavior and management is essential to play the leading role that promotes personal learning process to organizational learning, which will greatly influence the corporate performance of customer service.

By analyzing and sorting out the studies, we find knowledge sharing acts fundamentally on organizational learning that it can make the organization come up to a higher learning level. This promotion is hard to realize spontaneously, thus the management needs to involve as the external impetus. What's more, a higher level of organizational learning can bring out a more open and free learning culture, which will further facilitate knowledge sharing within touristic enterprises.

\section{Knowledge Sharing and Service Innovation}

Service innovation refers to organizational innovations as well as service product and process innovations, and the management of innovation processes within service organizations. Service innovation capacity is one of the core impetus of enterprise operation and knowledge has a close relationship with service innovation behavior even with the business performance of a company. In tourism industry, knowledge sharing within a enterprise can promote the interaction and application of knowledge, which makes employees have the chance to get in touch with knowledge from different fields and thus trigger their innovative behavior. Furthermore, effective service innovation could bring forth new products and techniques, as well as renovate the outdated organizational structure and operation method, which will further realize higher service quality and touristic satisfaction. At present, previous studies in academia can be boiled down to two topics, one is to focus on the mechanism of how knowledge sharing acts on service innovation performance. Another topic is to explore the factors that can mediate this mechanism, which means to study the mediating variables between knowledge sharing and service innovation.

\subsection{Knowledge Sharing and Service Innovation Performance}

Service innovation firstly originates from knowledge renewal and knowledge renewal is derived from knowledge sharing. During this process, a person can share his hands-on knowledge by discussion, while for an organization, knowledge sharing needs to be based on team cooperation. By the means of cooperation and co-creation, one kind of knowledge can be updated to another new one by interacting and being modified constantly, which will make employees main- 
tain job satisfaction and compliance [30] and thus lead to the continuous knowledge renewal in an organization [31].

Theoretically, innovation depends on new knowledge creation. Hjalager pointed out that effective knowledge management can motivate the knowledge innovation of touristic destinations and enterprises, which enables them to gain high competitiveness. On this basis, Cooper suggested that the knowledge creation can engender innovation while the creation calls for the sharing of "knowledge flows". From the viewpoint of enterprises, Hu MLM [32] did a survey about knowledge sharing behavior and service innovation performance in hotel. The results showed that knowledge sharing has strong positive correlation with service innovation performance. More specifically, knowledge sharing can intrigue the service innovation behavior within a group and also the service innovation behavior performance relies on the mediation of organizational culture. Florian J. and T.L. Hill [33] took the enterprises in a touristic place as the case and studied their innovation behavior, status of these enterprises and the characteristics of knowledge and trust in their cooperation relationship. The results indicated that companies that have a high multiplicity of knowledge are more inclined to share knowledge and thus they are more likely to have cooperative innovation. From the micro-level of corporate operation, knowledge sharing can lead to the internal service innovation behavior and therefore enhance the competitiveness. From the macro-level of industry, knowledge sharing can construct the industrial cooperation model as well as set up a sustainable industrial cooperation system. Y. Higuchi and Y. Yamanaka studied the Japanese touristic industry and got the conclusion that practitioners in tourism urgently need to learn from the research results from tourism and other disciplines in order to develop products of high quality. Although, in most cases currently, touristic enterprises have scarce resource investment in a sustainable research cooperation system. There is also another case study based on three Norwegian whale-watching companies [34]. By illustrating the process of knowledge co-creation between researchers and firms, the author testified that knowledge sharing could happen throng intensive interaction and consequently the co-creation pays off in terms of innovation. For this reason, tourism practitioners are trying to share their knowledge, especially for tacit knowledge, with college researchers so that they can achieve a long-range value creation together. By creating a new value of touristic experience, practitioners and scholars can bring innovative touristic products of sightseeing. Even though these studies are merely several special cases based on tourism, they can be the pioneering empirical study in the field of sustainable tourism, knowledge sharing and relationship embedding.

\subsection{Knowledge Sharing, Service Innovation and Mediating Variables}

It is a new trend in academic circle to study the mediating variables between knowledge sharing and service innovation. Hu M.L.M. firstly introduced rela- 
tionship as a moderated mediating variable when he did a research on the relationship of knowledge sharing and service innovation. By collecting questionnaires from 1260 employees of 36 different international hotels in Taiwan and using SEM (Structural Equation Model) to analyze the data, the research found that relationship has significant correlation with both knowledge sharing and service innovation behavior and it plays the role of mediating the influence process from knowledge sharing to service innovation. Considering the strong mediating effect of relationship, Hu M.L.M. suggested that enterprises should build up positive relationship networks so that the ability and willingness of employees' service innovation can be promoted and the organization can apply the achievements in knowledge sharing to service innovation. Similarly, Wu C.F. [35] also studied the relationship between knowledge sharing and service innovation. The difference is, the author chose the tourism practitioners from both mainland China and Taiwan and took the diffusion of commercial ethics as the mediating variable. The research found that the knowledge sharing within touristic enterprises can promote the diffusion of commercial ethics effectively, and this kind of spread within or among organizations can stimulate service innovation behavior. That is to say, knowledge sharing could influence service innovation behavior through the mediating effect of commercial ethics diffusion. Additionally, knowledge sharing must rely on the mutual trust and harmonious organizational environment. The more altruistic the organization members tend to be, the more willing and frequent for them to share their knowledge. Therefore, touristic enterprises need to create a free and harmonious sharing environment to encourage their group members to share their knowledge and thereby achieve service innovation.

To sum up, the relationships of knowledge sharing and service innovation are conspicuous. Innovation relies on new knowledge creation and knowledge sharing can engender knowledge creation, which is the basic condition for service innovation. Furthermore, as the research went deeper, we find that there are some mediating variables like relationship and commercial ethics that can act on the positive correlation of knowledge sharing and service innovation, which enables the enterprises to have stronger service innovation ability and achieve performance improvement.

\section{Knowledge Sharing and Competitive Advantage}

Competitive advantage refers to the ability gained through attributes and resources to perform at a higher level than others in the same industry or market. Knowledge sharing brings forth competitive advantage. The competitive advantage of an enterprise is that the enterprise can obtain high-value returns at low cost, and innovation is exactly an effective means to reduce costs. Tourism has become an industry based on knowledge. Knowledge sharing is continuously reducing the cost of information generation and transmission, and it also catalyzes innovation. The current research in this area is mainly based on two paths. 
One is that knowledge sharing can enhance the convenience of information transfer and thus provide enterprises with a competitive advantage. Researches by Olsen and Connolly and Cooper proof this viewpoint. Another path is that knowledge sharing is conducive to the transfer of employee experience and customer information, so as to enable better customer management, and on this basis to increase customer satisfaction.

\subsection{Knowledge Sharing, Information and Competitive Advantage}

In the study of the hospitality industry, Olsen and Connolly believed that companies should regard knowledge and information as the key to successful business, but because hotels lack the ability to collect information and develop tacit knowledge, they need to have effective knowledge sharing behavior to promote the externalization of tacit knowledge and information transfer. Furthermore, the advent of the information era also requires tourism companies to share knowledge. Pyo, Uysal, and Chang pointed out in their research that due to the improvement of information and communication technologies, tourism increasingly requires the sharing, transfer, storage, and reuse of knowledge in order to enhance information dissemination capabilities and intrinsic value. In the study of the macro innovation behavior of tourism industry, Cooper and Hjalager believed that innovation relies on the creation of new knowledge, and new knowledge creation relies on the sharing of knowledge flows, so knowledge sharing can promote the occurrence of innovative behavior and thus enhance the competitive advantage of touristic destinations and travel companies.

With the widespread use of Internet technologies, online social networks (OSNs) are creating collective knowledge and become the main source of information for tourism decision-making and purchase of travel-related products and services [36] [37]. Scholars found that tourists and locals can share knowledge through social media interactions and generate tourist information to attract tourists [38] and also promote personal innovation [39]. In this process, social interaction factors and common values of tourists play an important role. At the same time, the perceived usefulness of technology products can also significantly affect the results of information transmission. Through the knowledge sharing of tourists on social media or online travel booking platforms, travel companies can build a good reputation and further transform it into a competitive advantage for the company.

\subsection{Knowledge Sharing, Customer Relationship and Competitive Advantage}

As a typical form of service industry, tourism industry is directly influenced by effective customer relationship management which acts as a competitive advantage to maintain the development of a touristic company. Knowledge sharing among tourism companies facilitates the transfer of customer information between upstream and downstream of the tourism supply chain, laying the foun- 
dation of improving customer satisfaction. From the viewpoint of knowledge sharing within tourism enterprises, Bouncken found out that hotels belong to knowledge-centralized industry through empirical research. Because knowledge is constantly exchanged and applied in the process of employees' exchanging experiences, most knowledge sharing behavior in hotels are related to customer relationship management, mainly focused on service quality and customer information of customer preferences, etc. Customer relationship management is one of the company's core competitive advantages. Edward C'S Ku and Fan Yiwen studied knowledge sharing and customer relationship management in travel agency alliances and found that knowledge sharing among organizations positively influence the successful customer relationship management, especially in the travel agency groups. By obtaining knowledge about market and product from suppliers, staff in travel agency can respond to customers' questions about products, thereby improving customer service level and performance of customer relationship management. For example, knowledge sharing between travel agencies and airlines can help deepen their cooperation, and then increase the market competitive advantage on both sides. In addition, good revenue management is the source of competitive advantage for tourism companies. Effective revenue management requires a knowledge-sharing culture to optimize task communication and information transfer. Florian Aubke [40] conducted a study on revenue management teams in hotel industry, and found that knowledge sharing is very important in the process of revenue management, and it has become one of the reasons to gain increasing corporate revenue.

Therefore, knowledge sharing is extremely important for the generation of competitive advantage of the enterprises. Knowledge sharing can reduce the cost and time of information transfer, improve the timeliness of decision-making, and promote the occurrence of knowledge innovation. On this basis, knowledge sharing can promote the innovation of tourism enterprises and gain competitive advantage. At the same time, effective knowledge sharing behavior can lay the foundation for excellent customer relationship management and internal revenue management and become an important source of competitive advantage for the company. It is worth noting that knowledge sharing is more necessary for the hotel industry due to higher costs and high staff turnover in the hotels.

\section{Discussion}

Although many literatures have carried out extensive and in-depth research on knowledge sharing and organizational learning, service innovation, and corporate competitive advantages in the tourism industry, the academic community has not yet built a suitable logical framework to summarize its mechanism. Based on the prior studies, we built a logical framework of "knowledge sharing organizational learning", "knowledge sharing - service innovation" and "knowledge sharing - competitive advantage" to sort out the mechanism of knowledge sharing in tourism enterprises. 
Knowledge sharing is not only the process of transferring knowledge, but also the process of helping knowledge recipients to internalize knowledge. Knowledge internalization is the learning process that knowledge receivers internalize and absorb knowledge through organizational learning, and then create new productivity. Therefore, knowledge sharing becomes an important part of organizational learning mechanism. Knowledge sharing usually involves as a basic role in organization learning process, providing the organization with a relaxing learning atmosphere and free movement of knowledge, thereby enhancing the learning efficiency of internal employees. Enterprises encourage their employees to participate in the process of knowledge sharing and improve their enthusiasm and participation in learning. As a result, employees' skills are continuously upgraded in communications, and ultimately the organizational learning performance and business service levels are improved. The improvement of the organizational learning level can provide an open and free learning culture for knowledge sharing, and correspondingly facilitate the sharing of knowledge within the enterprise. This constitutes the "knowledge sharing - organizational learning" system.

In tourism enterprises, employees can effectively disseminate information through effective knowledge sharing, and effective information sharing can reduce transaction costs within the company and establish trust relationships among internal members, thereby enhancing organizational commitment and promoting the occurrence of innovative behavior. Therefore, service innovation has become an important result of tourism knowledge-sharing behavior, which has been confirmed in the practice of tourism. In addition, effective knowledge sharing can be a powerful support for service innovation, and service innovation behavior will attract other individuals to learn and imitate, thus forming a new knowledge sharing behavior. From this perspective, the "knowledge sharing service innovation" system is also established.

Competitive advantage is the key to the sustainable development of an enterprise. Sharing knowledge in the enterprise can improve the ability of the enterprise to acquire external knowledge and ultimately promote the competitive advantage of the enterprise. In the practice, knowledge sharing in different dimensions also has different promotion effects on the generation of corporate competitive advantage. The internal knowledge sharing of tourism enterprise mostly occurs among employees. Because employees can easily share operational business knowledge, effective knowledge sharing can promote the improvement of employees' operational skills, and thus improve the level of customer service and customer relationship management, so as to maintain a stable source of tourists for tourism companies. What's more, knowledge sharing among tourism enterprise organizations can transfer information without barriers and ensure the timeliness of decision-making. In addition, when a company has a certain competitive advantage, in order to maintain and expand its current competitive edge, companies will continue to promote knowledge sharing and create a free and 
open environment to ensure that knowledge sharing occurs. Thereout, a "knowledge sharing - competitive advantage" system is built.

By comparing the above systems, we can find that the establishment of these three systems is a two-way interactive process that means, the two sides can transform with each other, which determines the sustainability of the process of knowledge sharing. On the other side, there are also endogenous connections between organizational learning, service innovation, and competitive advantage. In tourism enterprises, the improvement in the efficiency of organizational learning will undoubtedly strengthen employees' service skills and thus promote service innovation behavior. The occurrence of service innovation behavior will directly lead to an increase in the competitive advantage of the enterprise. Enterprises will keep efficient organizational learning in order to maintain their competitive advantage. Therefore, we find that "organizational learning - service innovation - competitive advantage" can form a closed loop, and knowledge sharing will be in the core position in this loop (Figure 2). On the one hand, knowledge sharing behavior has become the starting point and the driving force for the running of the closed loop. Through the sharing of knowledge in the enterprise, the organization's learning efficiency can be improved, which in turn affects service innovation and competitive advantage. On the other hand, knowledge sharing has become an important bridge for the three factors, which means it can mediate the correlation between knowledge sharing and organizational learning, service innovation, and competitive advantage, so as to ensure the loop to run smoothly.

\section{Conclusions}

Numerous existing literatures believe that knowledge sharing has become an

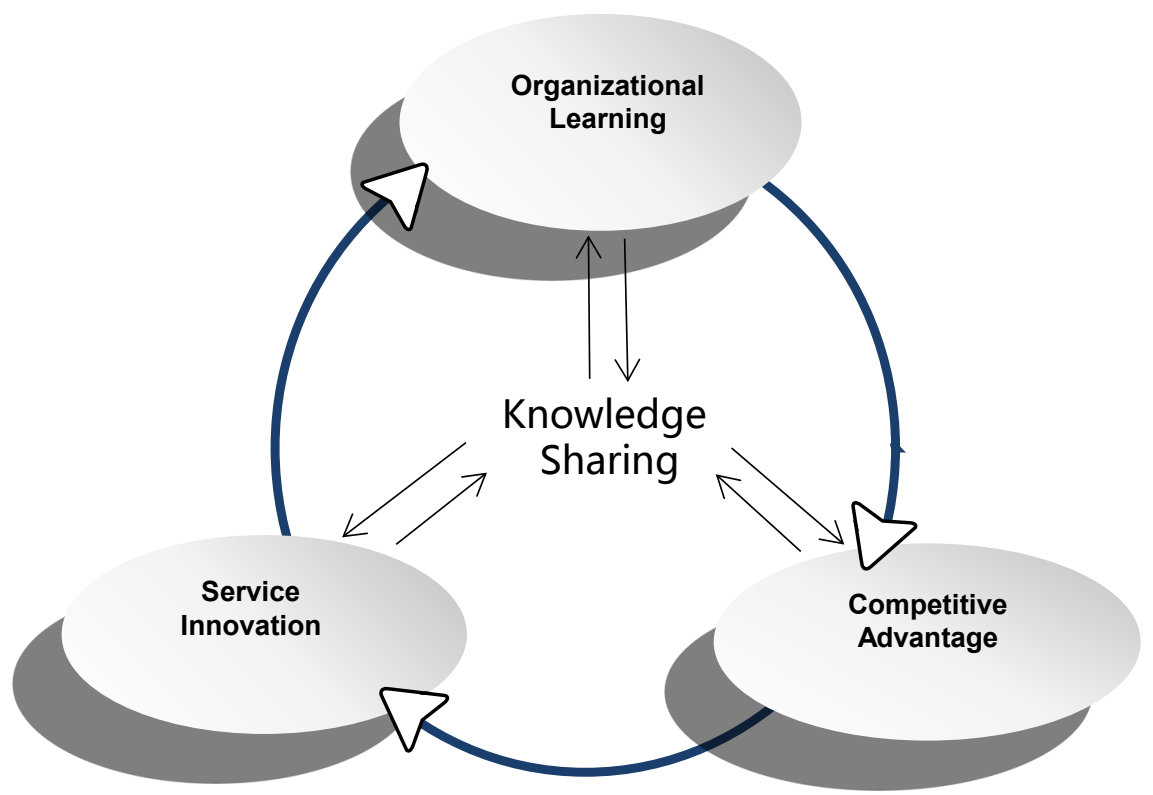

Figure 2. The closed loop of the research framework. 
important factor influencing the organizational learning and service innovation of tourism enterprises. At the same time, knowledge sharing provides a core driving force for forming the competitive advantage of tourism enterprises. Although there are many academic literatures, there is still a lack of a suitable framework to sort out the research results. Based on the role of knowledge sharing, this paper summarized the knowledge sharing researches in tourism industry according to the framework of "organizational learning - service innovation competitive advantage", and then analyzed the existing research results. Through sorting out the literature, this paper found that it is possible to form a closed loop around "organizational learning - service innovation - competitive advantage" within tourism enterprises, and "knowledge sharing" is at the core of this loop, and it becomes the starting point and bridge for the loop operation. Therefore, in order to guarantee the closed loop of "organizational learning service innovation - competitive advantage" to operate for a long run, tourism enterprises must guide the knowledge sharing behavior and provide a flexible and free atmosphere of knowledge sharing to encourage sharing behavior.

There are still some problems and deficiencies in this paper. When searching for relevant literature, this review used knowledge sharing as the keyword. However, some literature does not directly mention knowledge sharing, but conducts similar research based on the expressions of experience promotion, innovation diffusion, etc. This may lead to the omission of some relevant articles. In terms of literature retrieval, a more comprehensive search with other synonymous keywords can also be added. In conclusion, this article aims to review the research results of knowledge sharing in tourism and sort out the research actuality and future trends so as to provide reference for knowledge sharing both in practice and academia.

\section{Funding}

This paper is sponsored by China National Social Science Fund "Knowledge Transfer and Governmental Functions in Tourism Targeted Poverty Alleviation" (No: 16BGL112).

\section{Conflicts of Interest}

The authors declare no conflicts of interest regarding the publication of this paper.

\section{References}

[1] Bouncken, R. (2002) Knowledge Management for Quality Improvement in Hotels. In: Bouncken, R. and Sungsoo, P., Eds., Knowledge Management in Hospitality and Tourism, The Haworth Hospitality Press, New York, 25-59.

[2] Sungsoo, P., Uysal, M. and Chang, H. (2002) Knowledge Discovery in Database for Tourist Destinations. Journal of Travel Research, 40, 374-384. https://doi.org/10.1177/0047287502040004006

[3] Zander, U. and Kogut, B. (1995) Knowledge and the Speed of the Transfer and Imitation of Organizational Capabilities: An Empirical Test. Organization Science, 6, 
76-92. https://doi.org/10.1287/orsc.6.1.76

[4] Olsen, M.D. and Connolly, D.J. (2000) Experience-Based Travel. How Technology Is Changing the Hospitality Industry. Cornell Hotel \& Restaurant Administration Quarterly, 41, 30-40. https://doi.org/10.1177/001088040004100121

[5] Bartol, K. and Srivastava, A. (2002) Encouraging Knowledge Sharing: The Role of Organisational Rewards. Journal of Leadership \& Organizational Studies, 9, 64-76. https://doi.org/10.1177/107179190200900105

[6] Hjalager, A.M. (2002) Repairing Innovation Defectiveness in Tourism. Tourism Management, 23, 465-474. https://doi.org/10.1016/S0261-5177(02)00013-4

[7] Bouncken, R.B. (2002) Knowledge Management for Quality Improvements in Hotels. Journal of Quality Assurance in Hospitality \& Tourism, 3, 25-59. https://doi.org/10.1300/J162v03n03_03

[8] Smidts, A., Pruyn, A.Th.H. and van Riel, C.B.M. (2001) The Impact of Employee Communication and Perceived External Prestige on Organizational Identification. The Academy of Management Journal, 44, 1051-1062.

[9] Pan, G.W. and Laws, N.S.E. (2006) Understanding and Sharing Knowledge of New Tourism Markets. Journal of Quality Assurance in Hospitality \& Tourism, 7, 99-116. https://doi.org/10.1300/J162v07n01_06

[10] Magnini, V.P. (2008) Practicing Effective Knowledge Sharing in International Hotel Joint Ventures. International Journal of Hospitality Management, 27, 249-258. https://doi.org/10.1016/j.ijhm.2007.07.015

[11] Yang, J.T. (2009) Individual Attitudes to Learning and Sharing Individual and Organisational Knowledge in the Hospitality Industry. Service Industries Journal, 29, 1723-1743. https://doi.org/10.1080/02642060902793490

[12] Yang, J.T. (2010) Antecedents and Consequences of Knowledge Sharing in International Tourist Hotels. International Journal of Hospitality Management, 29, 42-52. https://doi.org/10.1016/j.ijhm.2009.05.004

[13] Chen, W.J. and Cheng, H.Y. (2012) Factors Affecting the Knowledge Sharing Attitude of Hotel Service Personnel. International Journal of Hospitality Management, 31, 468-476. https://doi.org/10.1016/j.ijhm.2011.07.005

[14] Ku, E.C.S. and Fan, Y.W. (2009) Knowledge Sharing and Customer Relationship Management in the Travel Service Alliances. Total Quality Management \& Business Excellence, 20, 1407-1421. https://doi.org/10.1080/14783360903248880

[15] Chalkiti, K. (2012) Knowledge Sharing in Dynamic Labour Environments: Insights from Australia. International Journal of Contemporary Hospitality Management, 24, 522-541. https://doi.org/10.1108/09596111211226806

[16] Higuchi, Y. and Yamanaka, Y. (2017) Knowledge Sharing between Academic Researchers and Tourism Practitioners: A Japanese Study of the Practical Value of Embeddedness, Trust and Co-Creation. Journal of Sustainable Tourism, No. 8, $1-18$.

[17] Yang, J.T. (2008) Individual Attitudes and Organisational Knowledge Sharing. Tourism Management, 29, 345-353. https://doi.org/10.1016/j.tourman.2007.03.001

[18] Sigala, M. (2008) Information Sharing and Knowledge Creation in Online Forums: The Case of the Greek Online Forum "Dialogoi”. Current Issues in Tourism, 11, 381-406. https://doi.org/10.1080/13683500802316006

[19] Cooper, C. (2006) Knowledge Management and Tourism. Annals of Tourism Research, 33, 47-64. https://doi.org/10.1016/j.annals.2005.04.005 
[20] Kim, T.T. and Lee, G. (2013) Hospitality Employee Knowledge-Sharing Behaviors in the Relationship between Goal Orientations and Service Innovative Behavior. International Journal of Hospitality Management, 34, 324-337. https://doi.org/10.1016/j.ijhm.2013.04.009

[21] Kyoungjoo, L. (2016) Sense of Calling and Career Satisfaction of Hotel Frontline Employees: Mediation through Knowledge Sharing with Organizational Members. International Journal of Contemporary Hospitality Management, 28, 346-365. https://doi.org/10.1108/IJCHM-01-2014-0026

[22] Lee, S. and Kim, S.H. (2017) Role of Restaurant Employees' Intrinsic Motivations on Knowledge Management: An Application of Need Theory. International Journal of Contemporary Hospitality Management, 29, 2751-2766. https://doi.org/10.1108/IJCHM-01-2016-0043

[23] Hawkins, D.E., Scott, N. and Laws, E. (2006) Transferring Tourism Knowledge: The Role of Higher Education Institutions. Journal of Quality Assurance in Hospitality \& Tourism, 7, 13-27. https://doi.org/10.1300/J162v07n01_02

[24] Liu, C. (2001) The Study of Knowledge Sharing Willingness of Employees of International Tourism Hotel Industry in Taichung.

[25] Bilgihan, A., Barreda, A., Okumus, F. and Nusair, K. (2016) Consumer Perception of Knowledge-Sharing in Travel-Related Online Social Networks. Tourism Management, 52, 287-296. https://doi.org/10.1016/j.tourman.2015.07.002

[26] Yang, J.T. (2007) Knowledge Sharing: Investigating Appropriate Leadership Roles and Collaborative Culture. Tourism Management, 28, 530-543.

https://doi.org/10.1016/j.tourman.2006.08.006

[27] Yang, J.T. and Wan, C.S. (2004) Advancing Organizational Effectiveness and Knowledge Management Implementation. Tourism Management, 25, 593-601. https://doi.org/10.1016/j.tourman.2003.08.002

[28] Kim, T. and Lee, G. (2012) A Modified and Extended Triandis Model for the Enablers-Process-Outcomes Relationship in Hotel Employees' Knowledge Sharing. Service Industries Journal, 32, 2059-2090. https://doi.org/10.1080/02642069.2011.574276

[29] Zhao, H., Xia, Q., He, P., Sheard, G. and Wan, P. (2016) Workplace Ostracism and Knowledge Hiding in Service Organizations. International Journal of Hospitality Management, 59, 84-94. https://doi.org/10.1016/j.ijhm.2016.09.009

[30] Lee, K.J. (2017) Knowledge Sharing in Franchise System: Franchisee Self-Leadership, Satisfaction and Compliance. International Journal of Contemporary Hospitality Management, 29, 3101-3118. https://doi.org/10.1108/IJCHM-03-2016-0178

[31] Sadowski, S.T. (1995) The Knowledge-Creating Company: How Japanese Companies Foster Creativity and Innovation for Competitive Advantage. Academy of Management Executive, 9, 83-85.

[32] Hu, M.L.M. (2009) Knowledge Sharing and Innovative Service Behavior Relationship: Guanxi as Mediator. Social Behavior \& Personality: An International Journal, 37, 977-992. https://doi.org/10.2224/sbp.2009.37.7.977

[33] Zach, F.J. and Hill, T.L. (2017) Network, Knowledge and Relationship Impacts on Innovation in Tourism Destinations. Tourism Management, 62, 196-207. https://doi.org/10.1016/j.tourman.2017.04.001

[34] Hoarau, H. and Kline, C. (2014) Science and Industry: Sharing Knowledge for Innovation. Annals of Tourism Research, 46, 44-61.

https://doi.org/10.1016/j.annals.2014.01.005 
[35] Wu, C.F. (2016) The Relationship between Business Ethics Diffusion, Knowledge Sharing and Service Innovation. Management Decision, 54, 1343-1358. https://doi.org/10.1108/MD-01-2016-0009

[36] Braun, P. and Hollick, M. (2006) Tourism Skills Delivery: Sharing Tourism Knowledge Online. Education \& Training, 48, 693-703. https://doi.org/10.1108/00400910610710100

[37] Chiappa, G.D. and Baggio, R. (2015) Knowledge Transfer in Smart Tourism Destinations: Analyzing the Effects of a Network Structure. Journal of Destination Marketing \& Management, 4, 145-150. https://doi.org/10.1016/j.jdmm.2015.02.001

[38] Edwards, D., Cheng, M., Wong, A.I., Zhang, J. and Wu, Q. (2016) Ambassadors of Knowledge Sharing: Co-Produced Travel Information through Tourist-Local Social Media Exchange. International Journal of Contemporary Hospitality Management, 29, 690-708. https://doi.org/10.1108/IJCHM-10-2015-0607

[39] Sigala, M. and Chalkiti, K. (2015) Knowledge Management, Social Media and Employee Creativity. International Journal of Hospitality Management, 45, 44-58. https://doi.org/10.1016/j.ijhm.2014.11.003

[40] Aubke, F., Wöber, K., Scott, N. and Baggio, R. (2014) Knowledge Sharing in Revenue Management Teams: Antecedents and Consequences of Group Cohesion. International Journal of Hospitality Management, 41, 149-157.

https://doi.org/10.1016/j.ijhm.2014.05.010 